\title{
The advantage of modern progress on occupational safety and health with the help of online applications/platforms
}

\author{
Andrada Denisa Băbuț $^{1 *}$, Cristian Raul Cioară ${ }^{1}$, and Daniel Florea ${ }^{1}$ \\ ${ }^{1}$ National Institute for Research and Development in Mine Safety and Protection to Explosion - \\ INSEMEX, 32-34 G-ral Vasile Milea Street, Petroșani, Hunedoara, Romania
}

\begin{abstract}
The evolution of information and communication technologies has led to the development of an increasing number of interactive online tools, and the occupational safety and health sector is no stranger to this trend. In the context of the COVID-19 pandemic and the transfer of a very large percentage of activities online, the idea of this paper starts from the need to easily manage the documentation on safety and health at work, staff and work points, thus reducing time and eliminating travel costs and last but not least avoiding physical contact as much as possible, by implementing an application or a platform at institution level. These online tools are addressed to all employers, employees, workers and public authorities with responsibilities in the field of occupational safety and health.

Although at present the specialists in the field of OSH face bureaucracy, being a rather complex field and at the same time so necessary in the practice of service activities, online training platforms or applications come to their aid to streamline the process of OSH training and testing of knowledge.

Due to modern progress, training will be possible from any point of work, requiring only an internet connection.
\end{abstract}

\section{Introduction}

With the emergence of new regulations in the field of labor relations (H.R) and occupational safety and health provided in the O.U.G. 36/06.05.2021 on the use of advanced electronic signature or qualified electronic signature accompanied by the time stamp and qualified electronic seal of the employer, professionals working in the field of occupational safety and health, but also their employers and employees, have an electronic alternative. They have at their disposal applications / platforms, which allow the upload of the necessary documentation to compile the file for OSH activity, as well as the realization of all types of training provided by law, having access to the information entered in the application / platform in conditions of maximum data storage. Under the pressure of the pandemic we had to learn and adapt to use digital technology more often in everyday life.

* Corresponding author: andrada.babut@insemex.ro 
Moreover, in the professional activity it is necessary to adapt to the new, the integration in the "digital world" being absolutely necessary and at the same time we need to be aware of the role of digitalization in the field of occupational safety and health and be open to this new challenge.[9]

Compared to the safety measures imposed at national level at this time, it can be ensured that labor inspectors can use the online environment legally, without the need for physical interaction with the employer in order to provide the necessary documents to carry out the control and without the possibility of transmitting the COVID-19 virus through these documents.[3]

\section{Description of OSH applications / platforms}

When we talk about OSH training we refer to on-the-job training, regular training, etc. With the advancement of technology, modern progress in the field of OSH has not stagnated, but a topical way has been sought through which with the help of these online OSH applications / platforms, the work will be much easier for those in this field being able to do online training. You can also see who has been trained and who has not, when an employee was last trained, so that the OSH documentation can be kept under control and we will have the guarantee that the employee has completed all the training. [1]

In Romania, we started talking about digitalization 4 years ago, when the idea of finding intelligent solutions for managing these activities took shape, solutions that at that time aimed only at streamlining the employer's costs, the way it is used by specialists in this field, how to train the worker to be protected from risks in carrying out work tasks and to identify a fast, efficient and legal way to facilitate the employer's ability to interact remotely with own employees, business partners or state institutions, etc. [3]

These applications/platforms are useful for a company, an OSH inspector, an employee, but especially for labor protection services. Safety and health at work, together with emergencies (SU), together with fire prevention and extinguishing (PSI), are quite complex areas and yet so necessary in the practice of service activities, referring to both heavy industries or corporations, as well as small or newly established companies. [1]

With the help of online management applications / platforms in labor protection and emergencies, we can make our work easier and halve the response time, as well as the costs in these areas.

In order to be able to access and benefit from them, a first step would be to enter OSH documents that must include OSH decisions, instructions and evaluations, in Word or PDF format, then to easily complete employee profiles you need to upload the Revisal File. After these steps already completed and the attachment of the questionnaires, the application/platform will generate the topics, trainings and tests, and to facilitate the training, the organization/departmental structure of the company can be created from the application / platform.

The platforms/applications must be equipped with advanced electronic signature validation functions, accompanied by the electronic time stamp according to EU Regulation $910 / 2004$ so that both the employee and the manager can electronically sign the documents.

In order for the application/platform to generate the reports, the following steps must be completed:

- Creating work points

- Adding employees

- Planning activities

- Introduction of equipment

The report module provided instantly by the application/platform helps to operatively know any aspect related to work safety, so that immediate action can be taken to prepare an 
activity. All reports are online, so accessible from any operating system connected to the Internet. Reports can be downloaded and sent via email, or through the application's cloud network using internal messaging. [1]

Also, the downloaded reports are already pre-completed with the name of the working point, the date of the report, etc., and they will be signed as if they were prepared and then presented to the person concerned.

In most Member States, the application of OSH legislation depends on an employment relationship, which is more difficult to establish in the context of certain particularities of online platforms, such as the duality of stakeholders and the temporary nature, informality, autonomy and mobility of work. [4]

\section{The advantages of implementing an SSM application / platform}

When it comes to embracing 'digital' in health and safety, there is a lot to consider. Starting small, failing fast (if you have to) and learning from there. Digital can inform you along the way more seamlessly that paper based systems and controls can be presented - in much more interactive ways which stick in people's minds.[10]

The advantage of implementation is that everything is transferred to the online environment. For example, the SSM-SU/PSI training has become an online training framework. Labor protection service companies can quickly check on trained people.

Among the many advantages of online OSH applications/platforms is first of all the easy organization of information through an electronic document structure, easy to access and verify, automatically monitored, thus streamlining the work process. Documents will be secured by cloud storage with automatic backup, significantly reducing the risk of losing documents. Once the employee is entered in the employee menu, he can be assigned to a work point/compartment. Subsequently, if the workplace, compartment, area or workplace is changed, the employee is reassigned and will be assigned to another workplace or compartment. [1]

The advantage of SSM online applications/platforms is that the employee's previous data is not lost. Instructions and tests are kept safe.

Normally, signing, endorsing, approving and making available to the authorities the required documents takes quite a long time, but with the help of these applications/ platforms it saves time and the interaction with the Territorial Labor Inspectorates is much faster, more efficient, much more practical and transparent.

Another advantage is the unlimited number of documents that are under management, regardless of the number of employees and collaborators. Employee training and evaluations can be conducted remotely, as well as periodic testing through online questionnaires.

Checking the work protection sheets is done from the computer, from the laptop, tablet or even phone, we no longer need to travel to check them, so the cost of travel is eliminated, and with it the time.

SSM online applications/platforms easily meet the needs of a novice inspector as well as an expert in the field, some of which are listed below:

- All work points can be easily controlled from the application/platform, by predefined real-time auditing

- The training is done online, from any operating system connected to the internet

- Keep documents safe, all notes are stored in the cloud

- Predefined audit - prior notification system about planned activities

- With the help of the application / platform, fast reports can be generated in real time, from all work points 
- Using the schedule function, you can plan all the activity for a whole year and receive notifications with what is to be done

- After uploading specific documents they can be seen in real time even from a work point that is located hundreds of kilometers away

- Half working time

- Elimination of travel, costs of sending documents and giving up printed documents

- Guided by predefined modules that help you how to do and what to do

- Employees can be tested online, the correction is done automatically, and the results will be sent by e-mail. [1]

Working on online platforms offers the advantages of flexibility in terms of working time and place of work, but there are many cases where this flexibility is imposed on the worker. [4]

Digitization also offers important opportunities such as facilitating the work of the labor inspectorate. Digital technologies now provide essential services to all sectors of our economy and society. These developments can create new challenges for OSH and its management. The rate at which these developments are taking place is faster than ever. [5]

\section{Digitization and use of the online environment and electronic signature}

Following the study, at present, there are several applications and online platforms through which it can be much easier to manage OSH activity, but which until 2021 did not have a legal regulation that could give the possibility to all those who want to use the online environment to manage these activities to do so in full compliance with legal provisions, without the possibility that the validity of documents issued, signed and administered electronically is not recognized and does not produce the same effects, provided by law, as physical documents .

The new legislative framework offered by GEO 36 of 06.05 .2021 regarding the digitization of the Occupational Safety and Health activity, contains explicit provisions that allow the digitization and use of the online environment and qualified electronic signatures for issuing and administering any document to which we wish to give validity legal. Thus, the barrier set by the provisions of GD 1425/2006 on the Methodological Norms for the application of Law 319/2006, on Safety and Health at Work, which requires the recording of training on paper with "pen with paste or pen", is removed.

Currently, the number of economic operators spending significant resources of time and money on signing and managing paper documents is significant. Moreover, in the current pandemic context, when a large part of employees work in telework, both for them and for employers, it is inefficient for employees to show up at the office just to sign documents.

We also constantly keep in mind that, in order to protect the environment, limiting paper consumption must be a real concern for everyone. [5]

The numerous body of online applications and platforms that aim at occupational safety and health and is currently on the Romanian market, is becoming increasingly sought after by employees with responsibilities in this field to facilitate their work and to keep under control occupational safety and health management.

SSM.ro is the first computer application in Romania that creates the possibility of organizing the activity regarding safety and health at work. In order to be able to use the application from anywhere, it is necessary to start creating an account by receiving an SMS and e-mail with the invitation to connect to the application. 
Fig. 1. Account registration and creation

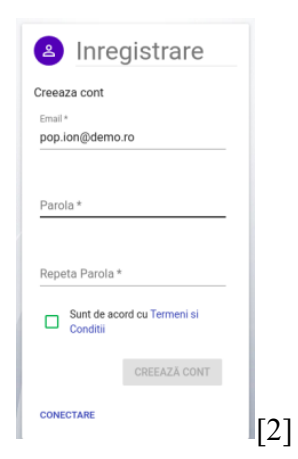

In the next step it is necessary to complete the profile with personal and company data, regardless of whether the role of the user is an employee, inspector or administrator.

Once the profile has been completed, the training documents must be uploaded and completed by the employees, who will eventually complete the test questionnaires.

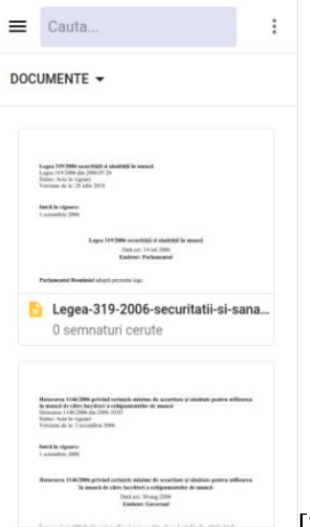

Fig. 2. Upload documents

At the end, the employees will send the results of the tests for validation, each user digitally signing the training sheets.

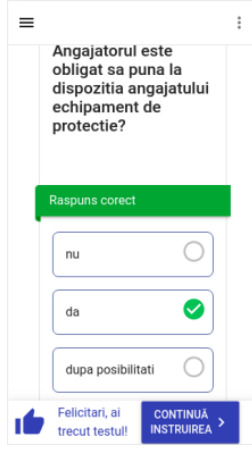

Fig. 3. Validation of documents

Also another example is Easy SSM, an online management application for the protection of work and emergencies. After entering the company data, work points, employees, in order to complete the online training SSM-SU / PSI, the job manager or 
designated specialist must first receive an email notification, and then each employee will receive the necessary instructions, will automatically train and take the test online.

The Euramis platform, like the other applications and platforms listed above, is easy to use, regardless of the operating system, browser or device with which the user connects, having access at any time of the day and from any location, only of an internet connection. The website of the Euramis platform is accessed and the authentication with the chosen email address and password will take place. After authentication we will have access to complete, updated documents that comply with legal provisions, and the documents created and stored by the user on this platform will be protected, saved and will not be lost.

The verification and testing of the way in which the employees have acquired their knowledge in the field of OSH and SU, both in the introductory-general training, as well as in the on-the-job and periodic training, can be done through online tests.

Specifically, the employee will $\log$ on to the platform and complete the test or tests assigned online, depending on the position in which he is employed. [6]

\section{Conclusions}

In this article we have presented some basic aspects, reflections and vectors of interest related to the significant contribution of the implementation of an online OSH application / platform, improving performance in the field of occupational safety and health.

Following the analysis, there are a variety of applications and platforms that can help OSH staff to facilitate their work and have better control over occupational safety and health documentation.

Digital technologies can drive OSH efforts in a variety of ways, for example, by protecting workers from hazardous work situations through innovative ways of monitoring exposure or by improving the quality of work as a result of relieving workers of repetitive tasks or routine. Digital technologies and new forms of work could also enable workers to enjoy greater autonomy and flexibility or facilitate access for a more diverse workforce to the labor market, especially for vulnerable groups such as people with disabilities, elderly workers and people with home care tasks. Digitization also provides opportunities for increased efficiency in OSH training, advanced workplace risk assessment, communication and OSH inspections. [4]

Preparing for these changes is essential for the development of proactive systems that can protect workers, prevent accidents and disease, and promote the well-being of workers. [8]

\section{References}

1. www.easyssm.ro [Accessed 2.06.2021]

2. www.ssm.ro [Accessed 2.06.2021]

3. www.ekronomica.ro [Accessed 7.06.2021]

4. https://osha.europa.eu/ [Accessed 15.06.2021]

5. www.juridice.ro [Accessed 6.07.2021]

6. www.euramis.ro [Accessed 6.07.2021]

7. W. Cockburn, OSH in the future: where next?, (March, 2021)

8. Sarah A. Felknor, Jessica M. K. Streit, L. Casey Chosewood, Michelle McDaniel, Paul A. Schulte, George L. Delclos and on behalf of the Workshop Presenters and Participants, How Will the Future of Work Shape the OSH Professional of the Future? A Workshop Summary, (September, 2020)

9. National Webinar, Digitization of labor relations and occupational safety and health in the context of new legislation, (May 2021, Brașov)

10. Paul C. 'Digital': a game changer for health and safety (October 14, 2019) 